\title{
Configuration of anchorage holes affects fixation of the acetabular component in cemented total hip replacement-A finite element study
}

\author{
R. MOOTANAH*†, J.K. DOWELL市, K. CHEAH§ and P. INGLE† \\ †Bioengineering Research Group, Faculty of Science \& Technology, Anglia Ruskin University, UK \\ $\ddagger$ Mid-Essex Hospitals Services, Broomfield Hospital, UK \\ §Capio Springfield hospital, UK \\ *Corresponding author Email: rajshree.Mootanah@anglia.ac.uk
}

\begin{abstract}
Our survey of current practice among UK orthopaedic surgeons shows wide variations in fixation techniques. The aim of this study is to investigate the effect of drilling different configurations of anchorage holes in the acetabulum on implant stability. To avoid variables that could incur during in-vitro testing, we used commercially-available COSMOS finite element analysis package to investigate the stress distributions, deformations, and strains on the cement mantle when drilling three large anchorage holes and six smaller ones, with straight and rounded cement pegs. The results, which are in line with our in-vitro studies on simulated reconstructed acetabulae, indicate better stability of the acetabular component when three larger holes than six smaller holes are drilled and when the necks of the anchorage holes are rounded. The longevity of total hip replacements could be improved by drilling three large anchorage holes, rather than many smaller ones, as initially proposed by Charnley.
\end{abstract}

Keywords: Cemented total hip replacement, Acetabular component fixation technique, Anchorage holes, Cement pegs, Finite element analysis, Hip prosthesis

\section{Introduction}

Long-term studies have shown that failure of the acetabular component in total hip replacement increases exponentially ten years following surgery [1] and occurs mostly at the bone cement interface [2], especially at the neck of the cement peg. Uncemented fixation of the acetabular component has become increasingly popular during the last decade; however, follow-up studies indicate that, although cementless fixation result in improved longevity, it is associated with higher rate of wear, resulting in osteolysis [3]. Biological response to polyethylene debris results in the formation of soft tissue membranes at the bone-cement interface, which can be identified by radiolucencies on clinical radiographs [4]. Hence there is a need to improve the stability of 
cemented fixation of the acetabular component.

It is commonly accepted that the problem surrounding acetabular fixation is technique [5, 6, 7]. Figure 1 shows a failed acetabular cup implant, which had been retrieved during revision surgery, showing the fractured cement peg. The fractured cement mantle had a typical fatigue fracture surface, which could have contributed to the failure of the whole implant. During cemented fixation, anchorage holes are drilled in the acetabulum floor, then cement is introduced and pressurised to create cement pegs within the anchorage holes. The cement mantle plays an important role in securing the acetabular component in the pelvic bone and transferring the compressive loads associated with the subject's body weight from the femoral head to the pelvic bone. During normal activities, the bone-cement interface can experience high tensile, compressive and shear stresses. Tensile and shear stresses contribute most to failure of the interface since bone cement is weaker in tension and stronger in compression [8]. Fatigue failures are more common under tensile and shear stresses than under compression stress. The cement pegs have a major contribution in improving the torsional strength of the reconstructed acetabulum $[9,10,11]$. The contribution of cement pegs to the implant stability depends upon the stress distribution in the cement mantle, especially at the neck of the cement pegs where failure tends to occur. As the stress distribution becomes more even in the cement mantle and pegs, the overall performance of the fixation is improved.

Our previous studies show that torsional resistance at the bone-cement interface could be improved by creating cement pegs with chamfered or rounded necks, perpendicularly to the floor of the acetabulum [11] and by maintaining the subchondral bone [12]. Increasing the depth of the anchorage hole beyond a certain threshold value has little influence on the stress distribution in the cement mantle $[10,13]$. The torque strength of the reconstructed acetabulum also depends on the distribution of anchorage holes [16,17,20]. However, our survey of current practice among orthopaedic surgeons (525 respondents) shows wide variations in surgical fixation techniques, including the number, diameters and depths of anchorage holes drilled [14]. Traditional cementing technique involved drilling three $12.5 \mathrm{~mm}$ diameter anchorage holes [15] in the acetabulum while the modern cementing technique involves drilling about eight $5 \mathrm{~mm}$ diameter anchorage holes [16]. This seems to reflect on the survey of current practice on the cement fixation of the acetabular cup among orthopaedic consultants [14]. Our survey of current practice shows that there is an almost equal distribution of 23\% of Consultants drilling between 1 and 8 anchorage holes in the acetabulum. The remaining drill between 9 and 36 anchorage holes. Moreover, there is a higher tendency among older Consultants to drill fewer and larger anchorage holes, which corresponds to the traditional cementing technique. Because of the increasing demand for hip replacements, especially amongst the young, the longevity of the acetabular implant needs to be improved. Optimisation of surgical technique will result in further improvement in clinical results [17].

The aim of this paper is to evaluate the relative stability of acetabular implants with three large and six small anchorage holes (Figure 2), using three-dimensional finite element method. The results, verified by in vitro studies, could be used to provide guidelines for improving the distribution of anchorage holes, thereby increasing the longevity of the acetabular implant. 


\section{Finite element method}

Commercially available COSMOS finite element package was used for this study. The area of the hemi-pelvis which is of interest to this study consists of compact subchondral bone, porous cancellous bone of the acetabulum, cement mantle and pegs, ultra high molecular weight polyethylene (UHMWPE) cup and the head of the femoral prosthesis. For this comparative study, only the reconstructed acetabulum is considered, instead of the whole hemi-pelvis.

\subsection{Geometry}

The purpose of this study is to investigate the relative stability of the reconstructed acetabula, using different methods of fixation, rather than studying the absolute stress distribution for a particular fixation technique. Hence, in order to save computational time, without compromising the results, the acetabula is modelled in a hemi-spherical shape because, during surgery, the acetabula is reamed in a hemispherical shape to the notch, prior to cementing. The reconstructed acetabula finite element models consisted of the following parts:

- $27.8 \mathrm{~mm}$ head of femoral prosthesis.

- UHMWPE acetabular cup of internal diameter $28 \mathrm{~mm}$ and thickness $10 \mathrm{~mm}$. This left a gap of $0.1 \mathrm{~mm}$ between the head of the femoral prosthesis and the inner surface of the cup.

- $4 \mathrm{~mm}$ thick cement mantle with cement pegs.

- $56 \mathrm{~mm}$ diameter acetabulum, including $1 \mathrm{~mm}$ thick subchondral bone and anchorage holes.

The aim of this study is to predict, by three-dimensional finite element studies, the relative resistance to torque at the bone-cement interface of reconstructed acetabulae when different configurations of anchorage holes are drilled in the acetabulum. Hence, the following sizes and distributions of anchorage holes and cement pegs are considered for this paper:

- six $4 \mathrm{~mm}$ diameter, $10 \mathrm{~mm}$ deep anchorage holes and cement pegs with rounded necks, spaced $45^{0}$ apart;

- three $8 \mathrm{~mm}$ diameter, $10 \mathrm{~mm}$ deep anchorage holes and cement pegs with $1 \mathrm{~mm}$ rounded necks, spaced $120^{\circ}$ apart;

- three $8 \mathrm{~mm}$ diameter, $10 \mathrm{~mm}$ deep anchorage holes and cement pegs with sharp straight necks, spaced $120^{\circ}$ apart.

The areas of contact between the anchorage holes and the cement pegs are kept constant for the three models. The anchorage holes were created at an angle normal to the surface of the subchondral bone. This is based on our previous finite element study which shows that holes drilled at an angle resulted in an increase in the stress generated in the cement mantle and peg [11]. 


\subsection{Element size}

Four noded tetrahedral elements were used to mesh the subchondral and cancellous bones, cement, acetabular cup and head of the femoral prosthesis. $2 \mathrm{~mm}$ elements were used to mesh the thin subchondral bone in order to keep the aspect ratio low. As a result, the inner surface of the cancellous bone was also meshed with $2 \mathrm{~mm}$ sized elements in order to merge the nodes on these two surfaces. Following sensitivity analysis, the regions near to the neck of the cement pegs and anchorage holes were meshed with $1 \mathrm{~mm}$ sized elements because of high stress values in these areas. The remaining regions were also meshed with larger four noded tetrahedral elements while keeping the aspect ratio low.

105 node-to-surface contact elements were used on the inner surface of the acetabular cup and outer surface of the femoral head to represent contact and sliding between the two surfaces. Truss 3D elements, attached to the head of the femoral prosthesis on one end and fixed on the other, were used to stabilise the head of the prosthesis against unconstrained rotation.

\subsection{Material properties}

The material properties of the different parts of the models are retrieved from literature $[18,19]$, as shown in Table 1, and, for this comparative study, were assumed to be isotropic and homogeneous. In addition, the values for Poisson's ratio and Young's Modulus for the head of the femoral prosthesis are taken as 0.28 and 200 GPa, respectively.

\subsection{Boundary conditions}

The following boundary conditions were applied to the models:

- The outer surface of the acetabulum was constrained to zero-displacement in all directions.

- A resultant compressive force of $2000 \mathrm{~N}$, corresponding to 3 times body weight, was applied to the head of the femoral prosthesis. This compressive force is based on measured and calculated values of peak resultant forces acting on a reconstructed hip joint $[20,21,22,23]$.

- Forces of $36 \mathrm{~N}$ were applied to 2 diametrically opposed nodes located at the top inner surface of the acetabular cup to create a torque of $1 \mathrm{Nm}$, based on measurements of frictional moments of $0.9 \mathrm{Nm}$ and 0.4-1.2 Nm under a constant load of $890 \mathrm{~N}$ by Wilson and Scales (1970) [24] and Swanson and Freeman (1977) [25], respectively. Transient torques of up to $4 \mathrm{Nm}$ were recorded during the dynamic loading of acetabulum specimens in a wear simulator [26]

- The nodes on the outer surface of the subchondral bone were merged with those on the inner surface of the cancellous bone.

- Bonding between the subchondral bone and the cement mantle is obtained by mechanical interlock of the bone cement with the undulations formed on the surface of the acetabulum 
during the reaming process. Node-to-surface contact elements at the subchondral bone and cement interface were used to represent contact and limited sliding between the two surfaces. A sensitivity analysis was carried out on the value of friction between the two surfaces to ensure convergence of solutions.

- Cancellous bone consists of a honeycomb structure which allows good cement interdigitation during cement pressurisation. Perfect bonding between the cement peg and anchorage hole was modelled by merging the nodes on the inner surfaces of the anchorage holes and those on the outer surfaces of the cement pegs, thereby assuming good cement interdigitation.

- The nodes on the outer surface of the acetabular cup were merged with those on the inner surface of the cement mantle since this interface rarely fails.

- Node-to-surface contact elements, with very low coefficient of friction of 0.01 , were used between the inner surface of the acetabular cup and the outer surface of the head of the femoral prosthesis to simulate free movement between the two surfaces.

\subsection{Analysis}

In order to improve accuracy of the solutions, sensitivity analyses were carried out on the size of the elements, the modulus of elasticity of the truss elements holding the head of the femoral prosthesis and the number of time steps required for the non-linear solution. Non-linear analysis was run for each of the three models and the results were compared. Only tensile values have been considered in this study, given that cement is weak in tension and strong in compression. Compressive stresses were therefore not considered.

\section{Results}

Average of the ten peak values of the nodal displacement magnitudes, maximum principal tensile strains and tensile stresses were calculated for the three models. This was carried out by integrating these values for 10 elements subjected to peak stresses, but located in areas of low stress gradient near the anchorage holes, and dividing the results by the number of elements selected. These values were then normalised to the model with three $8 \mathrm{~mm}$ rounded anchorage holes, as shown in Table 2.

[Insert Table 2 about here]

Tensile stresses for the three models are shown in Figures $4(\mathrm{a}-\mathrm{c})$ on a scale of $0-20 \mathrm{~N} / \mathrm{mm} 2$. It can be observed that the cement mantle and pegs of the model with three large rounded anchorage holes was subjected to: lower peak stress values, lower strain values, lower nodal displacements, and more even stress distribution. 


\section{Discussion}

Table 2 shows the average of stress values around the neck of the anchorage holes of the model with six $4 \mathrm{~mm}$ diameter anchorage holes due to static loading is $36 \mathrm{~N} / \mathrm{mm} 2$ (or $36 \mathrm{MPa}$ ). In fact, fatigue failure is the most likely mechanism of failure of the cement. However, stress values for static failure are indications of stress values for fatigue failure. The fatigue ratio, which is the ratio of fatigue strength to tensile strength, has values of 0.25 to 0.5 , depending on the material $[27,28]$. The corresponding predicted tensile stress values due to fatigue loading would have been in the range of $8 \mathrm{MPa}$ to $16 \mathrm{MPa}$, which is above the endurance fatigue limit of acrylic bone cement of 6-15 MPa reported by Krause and Mathis (1988) [29]. By drilling three $8 \mathrm{~mm}$ diameter anchorage holes instead of six $4 \mathrm{~mm}$ diameter anchorage holes, the average of tensile stress values around the neck of the anchorage holes decreases from $31.2 \mathrm{~N} / \mathrm{mm} 2$ to $12.7 \mathrm{~N} / \mathrm{mm} 2$ (or $31.2 \mathrm{MPa}$ to 12.7 $\mathrm{MPa}$ ). The corresponding predicted tensile stress values due to fatigue loading would have been in the range of 3.2 MPa to 6.4 MPa, which is below the quoted endurance fatigue limit of acrylic bone cement.

The aim of this study is to investigate the relative stability of different distributions of anchorage holes; hence, the following assumptions were made:

- the notch of the acetabulum would not affect the comparative results, hence was not included in the models;

- the subchondral plate was assumed to be $1 \mathrm{~mm}$ thick throughout, to reduce variability. In practice, the subchondral plate is not uniform and is sometimes partially or fully removed while the acetabulum is being reamed. We decided to keep the subchondral bone in our FE models because results of our previous investigations highlighted the advantages of preserving the subchondral bone [12];

- an average elastic modulus of $0.05 \mathrm{GPa}$ was taken for the cancellous bone, although the density, hence the modulus of elasticity, of cancellous bone varies with location;

- because it is well accepted that stress level due to static loading is an indication of stress level due to fatigue load, static loads were applied to the models for this comparative study;

- for this comparative study, the results are based on a single load case, which corresponds to the peak resultant load acting on the hip joint [20-23].

- the size of acetabulum used in the FE model $(56 \mathrm{~mm})$ was above the average size. This is because, in a different study, the models were verified, using reconstructed Shetland pony acetabulae, which are slightly superior in size compared to the human specimens.

To our knowledge, no finite element studies have been carried out regarding the distribution of anchorage holes and our results could not be compared. However, various investigators, including the authors, have carried out laboratory investigations on the effect of the number of anchorage holes on stability.

The results predicted from our finite element analyses are in line with those of our in vitro investigations on reconstructed Shetland pony acetabulae [13]. Our results agree with the traditional cementing technique [15], 
whereby three $12.5 \mathrm{~mm}$ diameter anchorage holes were recommended and disagree with modern cementing techniques [30], whereby about eight $5 \mathrm{~mm}$ diameter anchorage holes are recommended. Our results also disagree with some previous studies where laboratory investigations were carried out to assess the importance of anchorage holes [31, 32], whereby similar values for the torque to failure were obtained for a reconstructed acetabulum, with no anchorage hole, and another with only one anchorage hole. One anchorage hole alone is unlikely to contribute to torque resistance. In fact, their raw data clearly show that, when cartilage is reamed and three anchorage holes are drilled, the turning moment to failure increases by $35 \%$ when the fovea is not cleaned. The turning moment to failure increases by more than $20 \%$ when the fovea is cleaned. It can also be deduced from Andersson and co-workers' data that, when the cartilage is not reamed and three anchorage holes are drilled, the turning moment to failure is even more pronounced (over 200\%). This could be because, when the cartilage is maintained, only the anchorage holes were contributing to resistance to torque and their effects became more visible.

Results from these 3D FE studies disagree with those of Pawluk et al. (1980) [33] and Oh (1983) [9]. Oh's (1983) results would have been more similar to those in this study if he had calculated surface area as that at the cement peg-anchorage hole interface rather than the cross-sectional area of the anchorage hole. In fact, cement interdigitation into the anchorage hole is more likely to contribute to resistance at the bone-cement interface than the cross-sectional area. Pawluck and co-workers obtained similar results because they calculated surface area in the same way as Oh did.

Our results agree with those of Mburu and colleagues. (1999) [10], although their experimental procedures were different in terms of specimens used and forces applied. The reason could be because Mburu and coworkers considered the area of contact at the cement pegs-anchorage holes interface in their investigations.

\section{Conclusions}

Results from our finite element analyses, which are based on the on measured and calculated values of peak resultant forces of three times body weight acting on a reconstructed hip joint during walking, show more favourable stress distribution in the cement mantle and pegs of a reconstructed acetabula with three larger (8 $\mathrm{mm}$ diameter) anchorage holes than one with six smaller (4 mm diameter) anchorage holes. These results have indeed been verified by in-vitro studies on reconstructed Shetland pony acetabulae. Our results also show lower peak tensile stress values in the cement mantle and cement pegs when the necks of the anchorage holes are rounded. The longevity of total hip replacements could be improved by drilling three large anchorage holes, rather than many smaller ones, as initially proposed by Charnley, and by rounding the necks of the anchorage holes. 


\section{Acknowledgements}

This research was sponsored by the Chelmsford Medical Education and Research Trust. The authors also acknowledge International Society of Biomechanics, for providing a matching dissertation grant, and Mr. Brian Watkinson and Dr Andrew New for their advice.

\section{References}

[1] Morscher E.W., 1992 Current status in acetabular fixation in primary total hip arthroplasty, Clin. Orthop., 274, pages: 172-187.

[2] Harkess J.W., 1998, Arthroplasty of hip. In: Canale ST. Campbell's Operative Orthopaedics, Mosby-Year Book, Inc., 295-425.

[3] Gaffey J.L., Callaghan J.J., Pedersen D.R., Goetz D.D., Sullivan P.M., Johnston R.C.., 2004, Cementless acetabular fixation at fifteen years. A comparison with the same surgeon's results following acetabular fixation with cement, J Bone Joint Surg Am;86-A(2):257-61.

[4] Maloney W.J., Schmalzried T., Harris W.H., 2002, Analysis of long-term cemented total hip arthroplasty retrievals. Clin Orthop Relat Res. 405:70-8.

[5] Ranawat, C.S., Deshmukh, R.G., Peters, L.E. and Umlas, M.E. 1995 Prediction of the long-term durability of all-polyethylene cemented sockets, Clin. Orthop. 317: 89-105

[6] Ritter M.A., Zhou H., Keating C.M., Keating E.M., Faris P.M., Meding J.B., Berend M.E. 1999 Radiological factors influencing femoral and acetabular failure in cemented Charnley total hip arthroplasties, J. Bone Joint Surg., 81(6): 982-986.

[7] Merrill A. Ritter, M.D., 2003, Acetabular options, J. Arthroplasty, 18 (3) Suppl. 1.

[8] Harper E.J., Bonfield W., 2000, Tensile characteristics of ten commercial acrylic bone cements. J. Biomed Mater Res 53(5):605-16.

[9] Oh A., 1983, Comprehensive Analysis of the Factors affecting Acetabular Cup Fixation and Design in Total Hip Replacement Arthroplasty: A Series of Experiment and Clinical Studies. 11th Open Scientific Meeting, Mosby.

[10] Mburu G., Hutchinson J.D., Aspden R.M.., 1999, Optimizing the configuration of cement keyholes for acetabular fixation in total hip replacement using Taguchi experimental design. Proc Inst Mech Eng [H]; 213 485-492.

[11] Mootanah R., Ingle P., Cheah K., Dowell J.K., Shelton J.C., 2000a, Cemented fixation of the Acetabular Cup in Total Hip Replacement: Improving The Anchorage Hole Profile Using Finite Element Method. Technol Health Care 8(6) 343-355.

[12] Mootanah R., Ingle P., Cheah K., Dowell J.K., Shelton J.C., 2000b, Using finite element methods to investigate the effect of removing the subchondral bone during the cemented fixation of the acetabular cup in total hip replacement. Proceedings of the 10th International Conference 
on Biomedical Engineering.

[13] Mootanah R., Ingle P., Allen E., Cheah K., Dowell J.K., Jarrett P., Shelton J.C., 2002, Total Hip Replacement: Improving the Cement Fixation of the Acetabular Component. Proceedings of the 13th conference of european society of biomechanics; Acta of Bioengineering and Biomechanics 4(1) 600-601.

[14] Mootanah R., Ingle P., Cheah K., Dowell J.K., Shelton J.C., 2004, Total hip replacement: results of a postal survey of current practice on the cement fixation of the acetabular cup in the UK. Hip International, 14 (3),: 155-162.

[15] Charnley, J., 1979, Low friction arthroplasty of the hip. Theory and practice, Springer, Berlin.

[16] Malchau H., Herberts P., 1998, Prognosis of total hip replacement - Surgical and cementing technique in THR: A revision-risk study of 148,359 primary operations. New Orleans: 65th Annual Meeting of the Americal Academy of Orthopaedics Surgeons.

[17] Morscher E.W., Wirz D, 2002, Current state of cement fixation in THR. Acta Orthop Belg. 68(1) 1-12.

[18] Choi, K., Kuhn, J.L., Ciarelli, M.J., Goldstein, S.A. 1990 The elastic moduli of human subchrondral, trabecular and cortical bone tissue and the size-dependency of cortical bone modulus, J. Biomech, 23 (11): 1103-1113.

[19] Dalstra M., Huiskes R., 1995, Load transfer across the pelvic bone, J. Biomech. 28 (6): 715724.

[20] Paul, J., 1967, Forces transmitted by joints in the human body, Proceedings of the Institution of Mechanical Engineers, Part H: Engineering in Medicine, 181(3): 8-15.

[21] Bergmann G., Graichen, F. and Rohlmann, A., 1993, Hip joint loading during walking and running, measured in two patients, J. Biomech. 28(8): 969-990.

[22] Stansfield, B.W., 2000, Hip joint forces of normal and hip replacement subjects. Ph. D. thesis, Bioengineering Unit, University of Strathclyde, Glasgow.

[23] Paul, J., 2000, Comparison of measured and calculated values of human leg joint forces Biomedical Engineering proceedings, 10.

[24] Wilson, J.N., and Scales, J.T., 1970, Loosening of total hip replacements with cement fixation, Clin. Orthop. 72: 145-155.

[25] Swanson, S.A.V.,Fre eman, M.A.R., 1977, The Scientific Basis of Joint Replacement, New York: John Wiley and Sons.

[26] Bowsher J.G., Shelton J.C., 2001, A simulator study of the influence of load and sliding speed on wear and frictional torque of smooth and roughened CoCrMo-UHMWPE total hip replacements. Wear 250, 167-179.

[27] Flinn, R.A. and Trojan, P.K. 1990 Engineering materials and their applications, 4th edition, Houghton Mifflin Company: 93-126. 
[28] Askeland, D.R. 1996 The Science and engineering of materials, 3rd edition, Chapman and Hall: 140-172.

[29] Krause, W., Mathis, R.S., 1988, Fatigue properties of acrylic bone cements: Review of the literature, J. Biomed. Mater. Res. 22 (A1): 37-53.

[30] Herberts P., Malchau, H., 1999, Modern Cementing Technique Total Hip Arthroplasty, ScandiMed AB.

[31] Andersson G.B., Freeman M.A.R., Swanson S.A.V. (1972),. Loosening of the cemented acetabular cup in total hip replacement. J Bone Joint Surg 54-B(4) 590-599.

[32] Harley, J..M. and Boston, D.A., 1985, Acetabular cup failure after total hip replacement, J Bone Joint Surg. 67-B, No. 2: 222-224.

[33] Pawluk, R.J., Tsitzikalikas, G., Eftekhar, N.S. 1980, The effect of surgical preparation on acetabular cup fixation, Transactions of the Orthopaedic Research Society meeting. 


\section{List of Figures and Tables}

Fig. 1: Fractured cement peg and cement mantle often causes the whole total hip replacement prostheses to fail.

Fig. 2: Configurations of anchorage holes considered in this study to investigate the effect of anchorage holes on stability of the acetabular component.

Figure 3: Exploded view and forces applied to the 3D model of the reconstructed acetabulum.

Figure 4a: Tensile stress distribution in the cement mantle and pegs of the FE model of reconstructed acetabula with 6 anchorage holes with rounded necks.

Figure 4b: Tensile stress distribution in the cement mantle and pegs of the FE model of reconstructed acetabula with 3 anchorage holes with rounded necks.

Figure 4c: Tensile stress distribution in the cement mantle and pegs of the FE model of reconstructed acetabula with 3 anchorage holes with right angled necks.

\section{List of Tables}

Table 1: Young's modulii and Poisson's ratios used for the different bones, implants and cement mantle in the FE model.

Table 2: Tensile stresses, nodal displacement magnitudes, and tensile strains for the FE models of the reconstructed acetabulae with three large rounded, six small rounded and three large, right angled anchorage holes. 
Figure 1

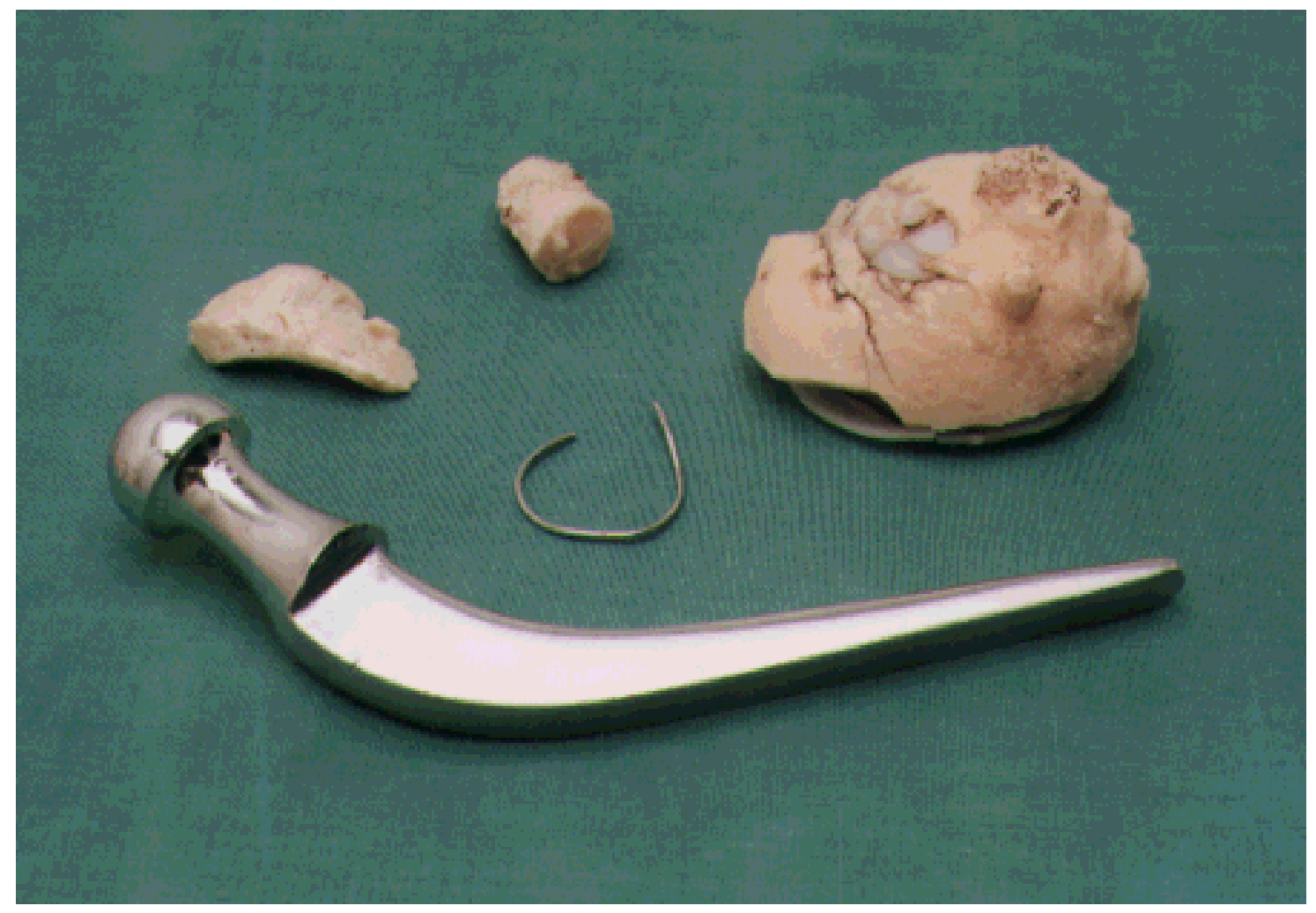


Figure 2
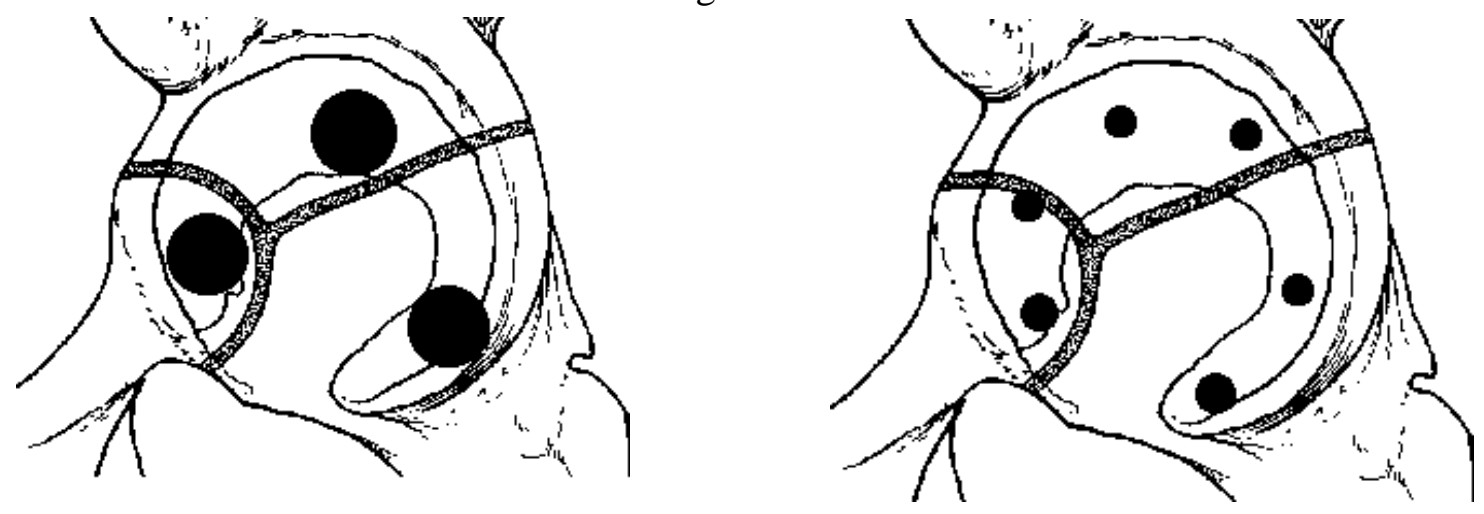
Figure 3

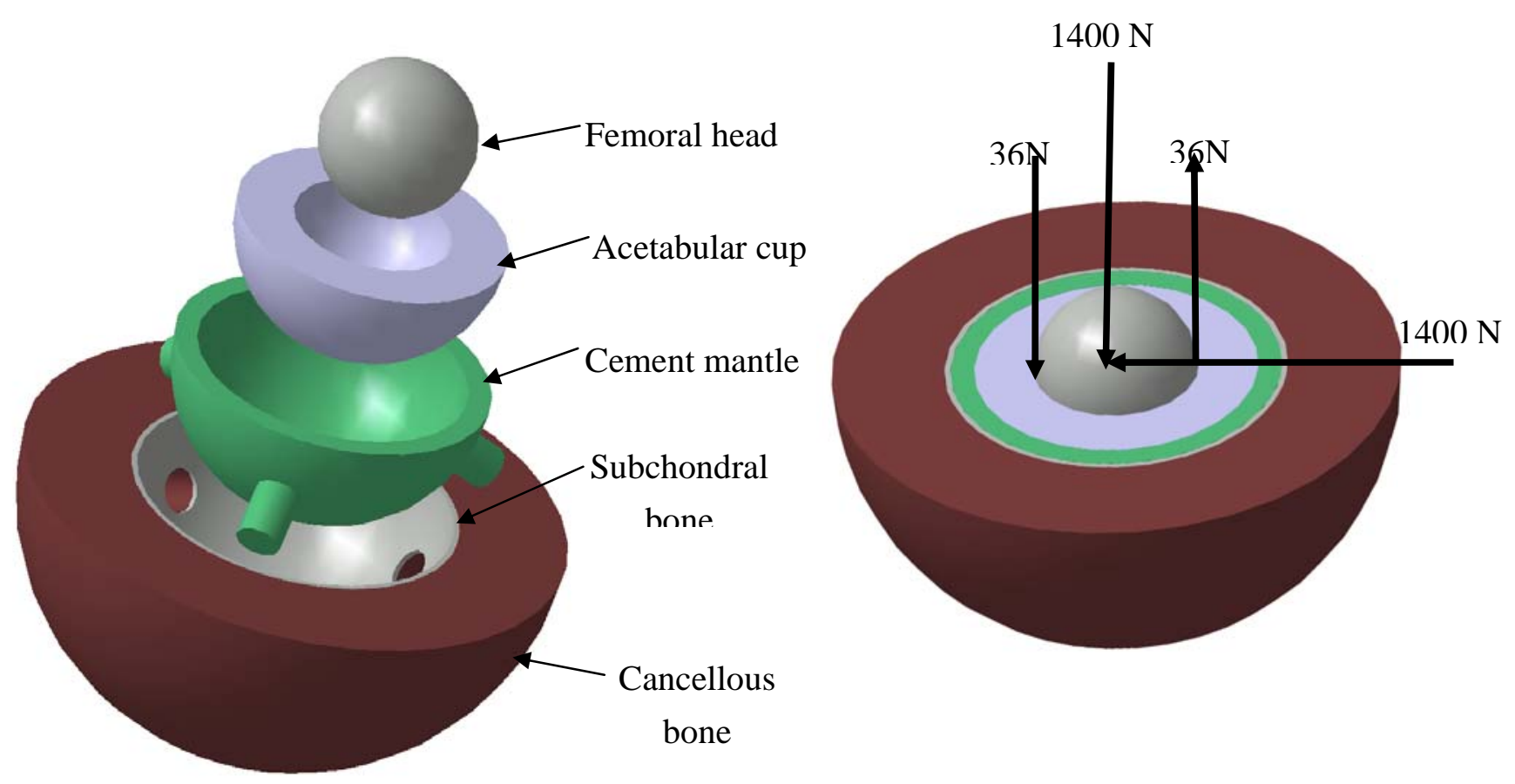


Figure 4a

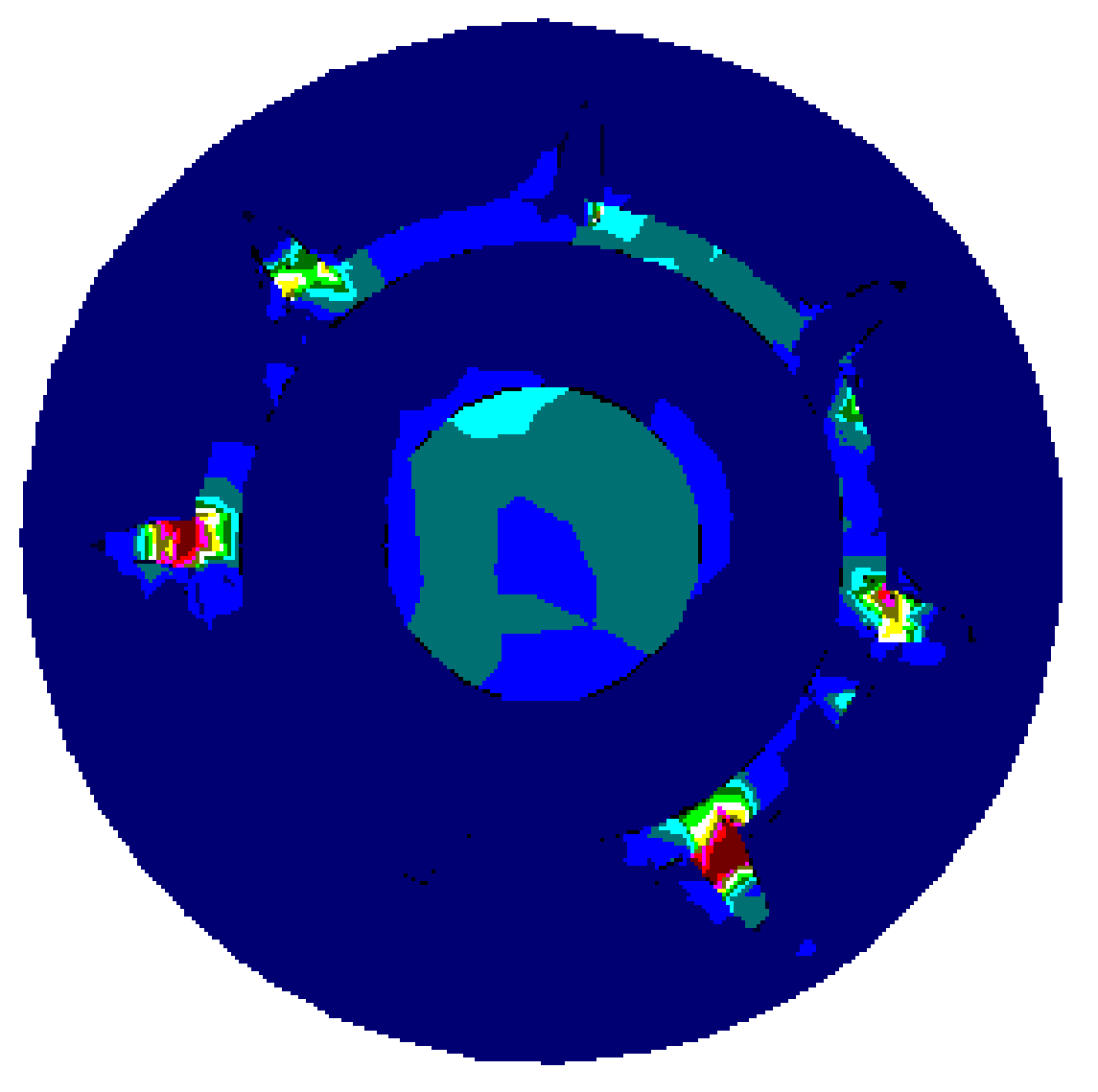


Figure 4b

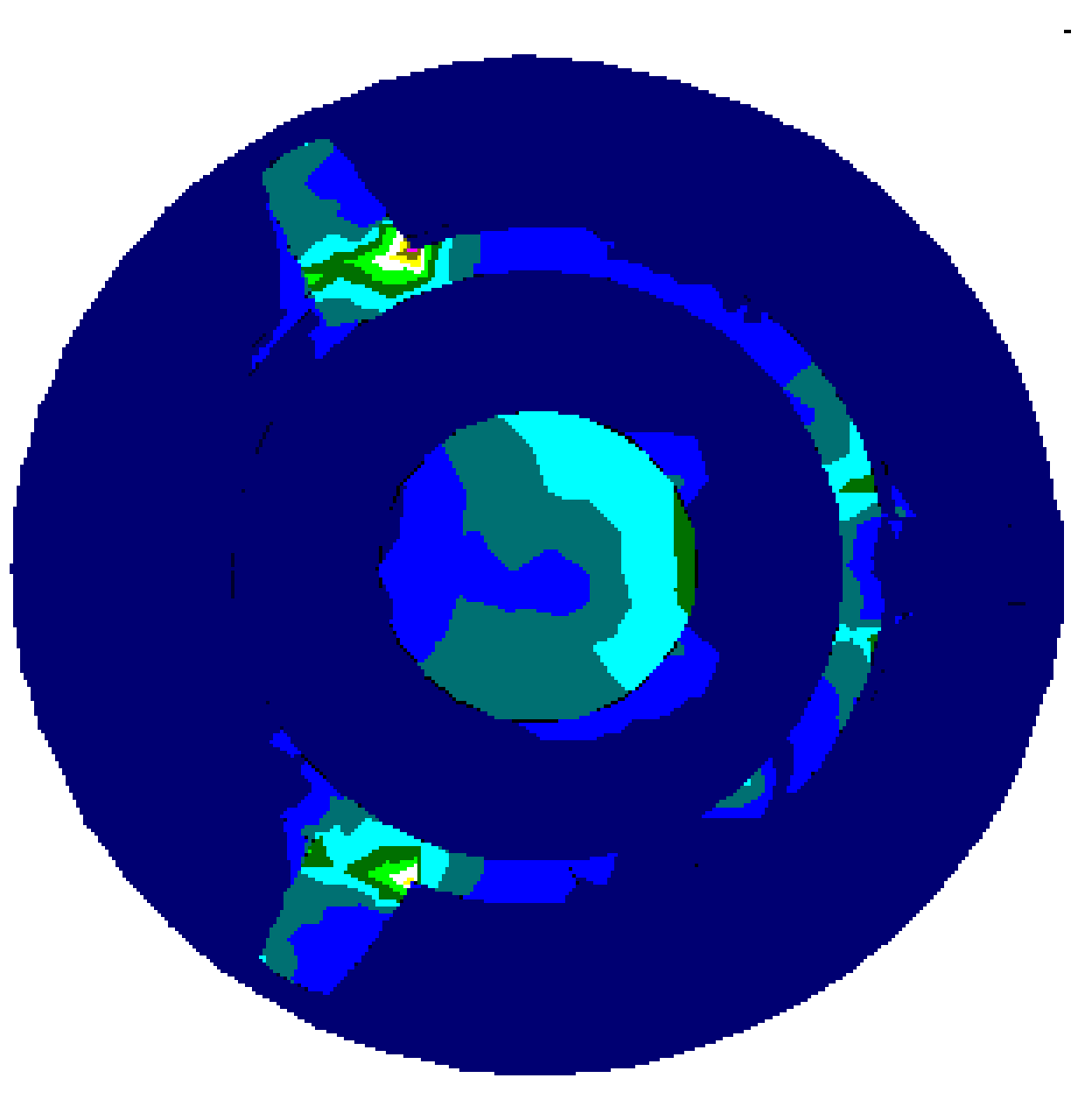


Figure 4c

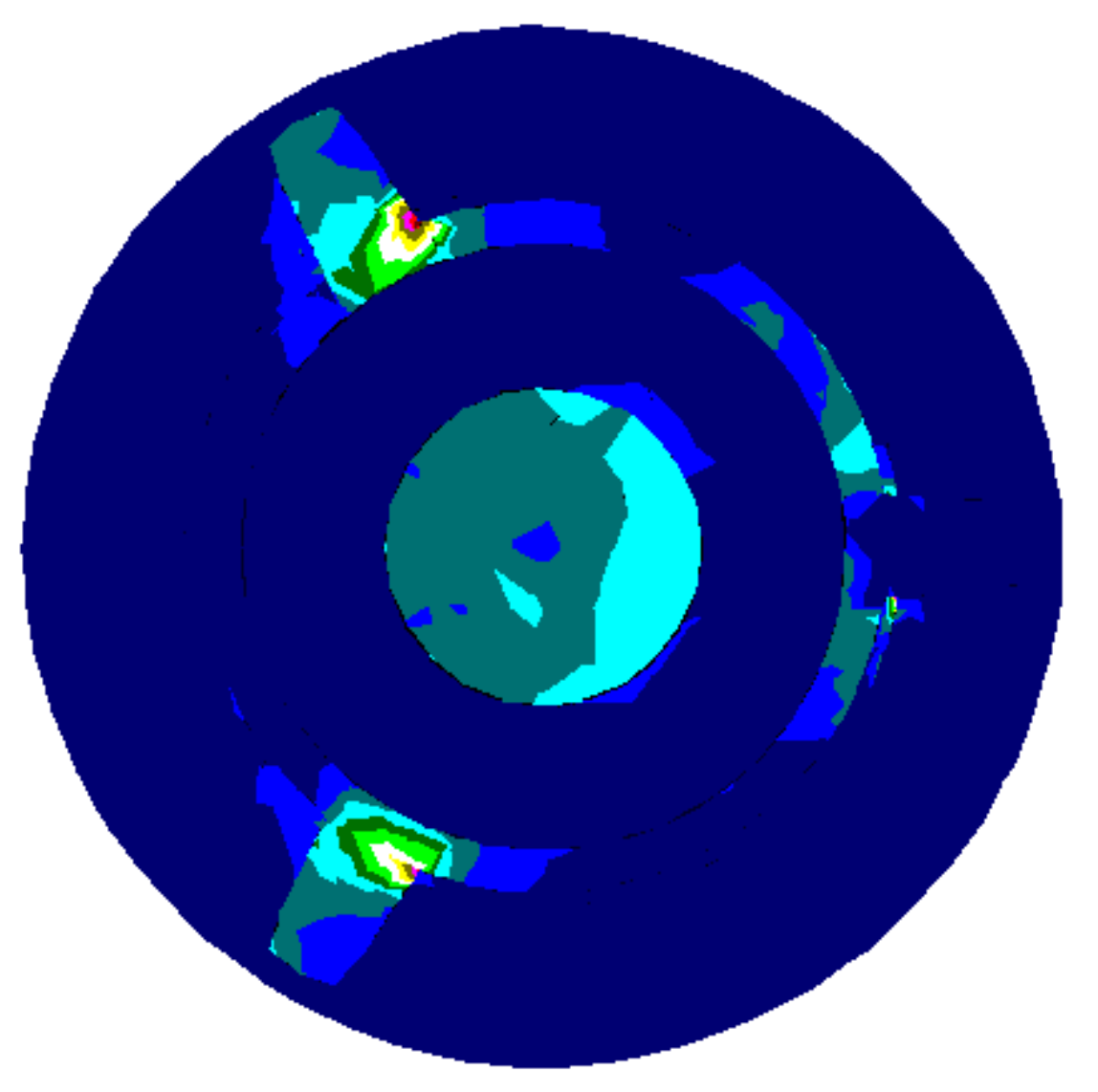

Pr- 1 חII 1

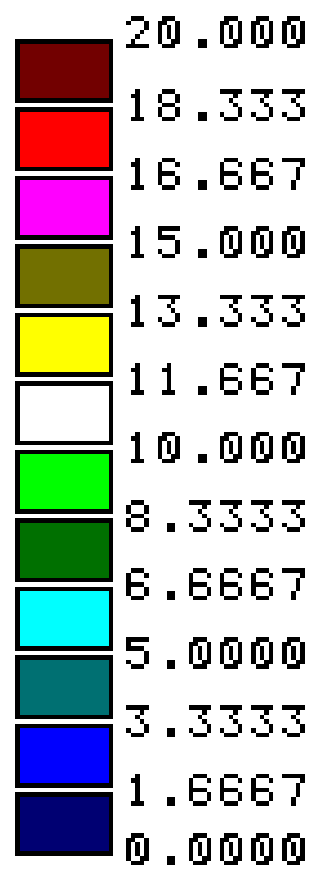


Table 1

\begin{tabular}{l|l|l} 
Part & $\begin{array}{l}\text { Elastic Modulus } \\
(\mathrm{Gpa})\end{array}$ & $\begin{array}{l}\text { Poisson's } \\
\text { Ratio }\end{array}$ \\
\hline Cancellous bone & 0.05 & 0.2 \\
\hline Subchondral bone & 1.15 & 0.3 \\
\hline Cement mantle and pegs & 2 & 0.3 \\
\hline Acetabular cup & 0.7 & 0.3 \\
\hline Head of femoral prosthesis & 200 & .28
\end{tabular}


Table 2

\begin{tabular}{|c|c|c|c|}
\hline & $\begin{array}{l}\text { Six } 4 \mathrm{~mm} \text { holes } \\
\text { with rounded } \\
\text { top }\end{array}$ & $\begin{array}{l}\text { Three } 8 \text { mm } \\
\text { holes } \quad \text { with } \\
\text { rounded neck }\end{array}$ & $\begin{array}{l}\begin{array}{l}\text { Three } 8 \quad \mathrm{~mm} \\
\text { holes } \\
\text { straight neck }\end{array} \\
\end{array}$ \\
\hline Tensile stress $\left(\mathrm{N} / \mathrm{mm}^{2}\right)$ & $31.20(152.9 \%)$ & 12.73 & $13.95(9.6 \%)$ \\
\hline Nodal displacement (mm) & $0.0984(60 \%)$ & 0.0616 & $0.0665(8.0 \%)$ \\
\hline Maximum principal strain & $0.0144(134 \%)$ & 0.00616 & $0.00673(9.2 \%)$ \\
\hline
\end{tabular}

